\title{
Urgences
}

\section{Casgrain : 2, Crémazie : 1}

Réflexions autour de l'histoire littéraire et de ses aléas

contemporains au Québec

\section{Marie-Andrée Beaudet}

Numéro 25, octobre 1989

Multiples de Hamlet

URI : https://id.erudit.org/iderudit/025548ar

DOI : https://doi.org/10.7202/025548ar

Aller au sommaire du numéro

Éditeur(s)

Urgences

ISSN

0226-9554 (imprimé)

1927-3924 (numérique)

Découvrir la revue

Citer ce document

Beaudet, M.-A. (1989). Casgrain : 2, Crémazie : 1 : réflexions autour de l'histoire littéraire et de ses aléas contemporains au Québec. Urgences, (25), 88-89.

https://doi.org/10.7202/025548ar d'utilisation que vous pouvez consulter en ligne.

https://apropos.erudit.org/fr/usagers/politique-dutilisation/ 
l'aliénation (côté "non-poème *) est aussi, est déjà une bataille dans la langue (côte "poème»): c'est bien " malgré moi , contre ma volonté et apour ne pas périr - (27 octobre 1954, p. 25) -, que, griffonnant *mes papiers du temps de la derision , j'ecris. On aura remarque l'anagrammatique sas qui va de "papiers * a "pas perir " et inversement.

9 "Amnésique Miron *: dans * Notes sur le non-poème et le poème (1965), Lhomme rapaillé, p. 126. «Archalque Miron *: dans *Epitaphe*, poeme publié dans L'arbre d parales, Flémalle (Belgique), n55, septembre 1985.

Casgrain : 2 , Crémazie: 1

\section{Réflexions autour de I'histoire littéraire et de ses aléas contemporains au Québec}

A lire ce qui s'écrit au Québec sur la littérature québécoise, j’ai de plus en plus l'impression que l'histoire littéraire d'ici n'appartient pas vraiment à la littérature ou, pour le dire autrement, que la littérature québécoise, dans l'esprit tout au moins d'un bon nombre de ceux qui se sont donné pour tâche de retracer les lignes de son parcours, ne trouve pas vraiment - pas encore? - sa place dans la vaste histoire des litteratures de ce monde. Quelque chose achoppe. Je sens de plus en plus nettement le malaise et les effets pervers d'un non-dit, d'une sorte d'inavouable douloureux qui mine la substance même du discours.

Ce que j'avance ne vise ni les theories ni les méthodes. De ce côté, les choses bougent. Pour s'en convaincre, il n'y a qu'à lire les actes du colloque sur l'histoire littéraire, tenu à l'Université Laval, en octobre 1986, et qui viennent d'être publiés aux Presses de l'Université Laval ${ }^{1}$.
Mes propos sont d'un autre ordre. Ils appartiennent a ce que l'on pourrait appeler l'observable des pratiques, tant celles de l'écriture que celles de la lecture. Pratiques que révèlent les rares publications destinées à un public débordant la communauté des chercheurs et des spécialistes de l'histoire littéraire.

Plus concrètement, et il n'y a qu'à regarder autour de soi, les travaux relevant de l'histoire littéraire (études, biographies ${ }^{2}$, etc.) n'intéressent grosso modo, que ceux qui s'y emploient. Ils n'intéressent guère les lecteurs (du moins, c'est ce que semblent penser les auteurs savants et les éditeurs de littérature générale). Ils n'intéressent pas plus - le fait mérite qu'on s'y arrête - les écrivains québécois ${ }^{3}$. Pourtant, ailleurs, on réaffirme l'importance des jeux complexes et vitaux, pour la littérature, de la filiation. A une question portant sur ses * maîtres * en littérature, l'écrivain espagnol Camilo José Cela, prix Nobel 1989, répondait récernment: "Tous ceux qui ont ecrit en espagnol avant moi, absolument tous, sans aucune exception. * Et il ajoutait ceci en quoi je crois aussi très fortement: "La littérature est une culture, une course à relais, il n'y a pas chez elle de génération spontanée ou de science infuse. " 4 Autrement dit, comme l'écrivait Mallarmé ou Valéry (joublie): La littérature naît de la littérature. Bref, qui s'intéresse à la littérature ne peut espérer avancer sans prendre en considération les acquis de ses prédécesseurs.

On parle peu, ici, d'histoire littéraire ou, si l'on en parle, c'est d'une manière gênée, réactivant à même les idées et hypothèses, les regrets d'un lointain mais toujours tenace échec. On laisse entendre (ces choses-là ne se disent jamais à voix haute) qu'il est dommage que 
cette littérature et que son histoire soient si peu interessantes, au fond, si peu littêraires! On sait que j'exagère à peine et que depuis Camille Roy, le ton de nos critiques et commentateurs a toujours été porteur d'une double contrainte: d'un côté, affirmer l'existence d'une littérature et, de l'autre, en dire l'impossibilité.

Alors que pour la majorité des peuples, l'histoire littéraire, tout comme d'ailleurs l'histoire sociale ou politique, constitue un lieu de reconnaissance, d'affirmation et, le mot n'est pas trop fort, de célébration, ici, on évite le sujet. Le désintérêt va jusqu'à cesser de l'enseigner et de la considérer comme une matière obligatoire, un savoir nécessaire. La difficulté, si on en croit ce qui transparaît en filigrane de bien des écrits sur notre littérature, viendrait de la nature même de son histoire. Jeune, terne et sans grâce, elle ennuie. $\hat{A}$ peine née, cette littérature aurait été détournée de son être propre et asservie à d'autres fins que les siennes. La pauvre! Casgrain l'a emporté sur Crémazie, et voila pourquoi votre fille est muette!

J'aime bien l'abbé Casgrain, moi. C'est un des grands personnages de notre histoire littéraire. Il faudra un jour lui rendre justice.

Ces réflexions, encore brouillonnes et fragmentaires, m'assaillent au moment où m'attend la lecture d'un essai dont le tire m'a immédiatement plu: Naissance d'une littérature ${ }^{5}$, et où je termine la rédaction d'une biographie, celle de Charles ab der Halden, ce critique français à qui Jules Fournier affirmait, par lettre ouverte, que la littérature "canadienne-française" n'existait pas. Cela explique mon humeur et mes propos. Je veux bien le croire.

Marie-Andrée Beaudet
1 Clement Moisan (sous la direction de), L'histoire littéraire. Théories. Méthodes. Pratiques, Quebec PUL, 1989 , 284 p.

2 Il y a heureusement des exceptions à la regle: certaing travaux consacrés à quelques rares auteurs aclassiques : connaissent une large diffusion. Je pense a la biographie que Paul Wyczynski a consacree a Nelligan.

3 Parmi ces exceptions, il faut compter celle de la rédition de La légende d'un peuple de Louis Fréchette dont l'idé revient au poete Claude Beausoleil. Louis Fréchette, La légende d'un peuple, introduction de Claude Beausoleil, Trois-Rivieres, F́crits des Forges, 1989, 281 p.

4 Camilo Jose Cela: «le suis un hêrétique *, texte et entrevue par Ramon Luis Acuna, Paris, Le figaro, 30 octobre 1989 , p. 7.

5 Rejean Beaudoin, Naissance d'une litterature. Essai sur le messianisme et les débuts de la littérature canadienne-française, 1850-1890, Montréal, Boreal, 1989, 209 p.

\section{Shakespeare en dic- tionnaire français}

Michel Grivelet, MarieMadeleine Martinet et Dominique Goy-Blanquet, Shakespeare de $A$ à $Z$... ou presque, Paris, Aubier, $1988,512 \mathrm{p}$.

\footnotetext{
Mais une bibliographie, méme sélective, eot exigé pour etre equitable beaucoup plus d'espace que n'en offre ce volume. Une estlmation récente (The Times Literary Supplament, 10 avril1987) fait état sur Shakespeare de 8,8 publications (ivres et articles) par jour.

Shakespeare de $A$ d $Z$... ou presque, p. 9
}

Les choses en sont donc là : dans un livre de plus de cinq cents pages consacré à Shakespeare, son époque, son milieu et son œuvre, 